\title{
PINTO, J. M.; SOUZA, S. A. de. (Org). Para onde vai o dinheiro? Caminhos de descaminhos do financiamento da educação. São Paulo: Xãma, 2014, 208 p.
}

\section{Por Bruna Caroline Camargo}

O financiamento destinado a educação é um tema que tem despertado inúmeros debates no ambiente acadêmico.

A obra "Para onde vai o dinheiro? Caminhos de descaminhos do financiamento da educação" busca discutir, em dez artigos, diversos temas relacionados ao financiamento da educação, os quais possuem ligações entre si, ou seja, todos os temas abordados estão interligados.

O primeiro artigo intitulado "Construção da complexidade do financiamento da educação pública no Brasil", autoria de João Antonio Monlevade traz um retrospecto histórico da construção do financiamento da educação no Brasil. Monlevade salienta que antes dos jesuítas, os indígenas já traziam aspectos relacionados ao processo educativo, objetivando reproduzir sua cultura, porém, não possuíam estrutura física.

O autor afirma que no período dos jesuítas, as arrecadações para suprir os gastos dos colégios e dos religiosos não eram suficientes. Dessa maneira, criou-se um sistema de autofinanciamento por meio de trabalhos escravos e posse de terras e rebanhos. Após a expulsão dos jesuítas criou-se o "subsídio-literário", um tributo destinado ao financiamento da educação. Todavia, Monlevade relata que esse tributo não permitia pagar adequadamente os mestres da escola.

A Constituição de 1934 trouxe avanços para a educação, pois foram vinculados percentuais a serem investidos pelos entes federados. Entretanto, como salienta Monlevade, após esse período tiveram-se momentos em que a obrigatoriedade dessas vinculações foram retiradas.

O autor aponta que por volta de 1960, a industrialização impulsionou a procura por escolas de ensino fundamental e médio público. Entretanto, os estados e municípios, responsáveis pela oferta dessas etapas do ensino não tiveram o crescimento na arrecadação de impostos proporcionais a demanda por matrícula. Monlevade chama esse período de "crise aguda do financiamento da educação pública".

Dentre outros elementos, o autor faz uma avaliação sobre o FUNDEF (Fundo de Manutenção e Desenvolvimento do Ensino Fundamental e de Valorização do Magistério) e FUNDEB (Fundo de Manutenção e Desenvolvimento da Educação Básica e de Valorização dos Profissionais da Educação). Monlevade afirma que o FUNDEF teve efeito nos municípios que pagavam salários muito baixos. Os estados que remuneravam melhor os professores perdiam recursos, ocasionado arrocho salarial e greves estaduais.

Quanto ao FUNDEB, o autor afirma que houve melhorias no custo-aluno anual e nos salários dos profissionais da educação.

O segundo artigo, intitulado "Desafios atuais referentes ao financiamento de uma educação de qualidade", autoria de Andréa Barbosa Gouveia e Angelo Ricardo e Souza, traz dados relativos à qualidade da educação. Os autores trazem dados do FUNDEB, mostrando que apenas dois estados - Roraima e Mato Grosso - ganham efetivamente com o fundo.

Os autores apresentam um índice, construído pelo Núcleo de Políticas Educacionais da Universidade Federal do Paraná, chamado de "Índice de Condições de Qualidade (ICQ)". Esse índice é composto por outros 
elementos, a saber: Índice de Condições Materiais e Estruturais (ICME); Índice de Condições do Professor (ICP); e Índice de Condições a Gestão Escolar (ICG).

Dessa maneira, Gouveia e Souza apresentam dados obtidos pelo uso do ICQ, nos anos de 2007 e 2009, em todos os estados e capitais brasileiras.

De maneira geral, os estados tiveram mais investimentos em educação em 2009 comparados a 2007. Nos dados apresentados pelos autores tiveram estados que obtiveram mais investimentos, porém o ICQ diminuiu; estados que tiveram queda no gasto-aluno mais aumento do ICQ; estados com queda no gasto-aluno e queda no ICQ; estados com crescimento do gasto-aluno e queda no ICQ; e estados com crescimento no gasto-aluno e aumento do ICQ.

Em relação ao ICME, todos os estados tiveram quedas significados de 2007 para 2009. O ICG apresentou melhor desempenho, de um modo geral, pois teve decréscimo em dois estados. Os autores mostram que ICME também teve queda nos municípios.

Na rede municipal, os autores afirmam que as condições do ICG são piores comparadas a rede estadual. Em contrapartida, o ICP possui um desempenho melhor nas redes municipais comparados as redes estaduais.

Por fim, Gouveia e Souza apontam que a qualidade da educação envolve um conjunto de elementos e mostram a importância do PNE frente a isso.

O artigo "Panorama do gasto público em educação na esfera estadual", autoria de Nalú Farenzena, traz a oferta e gasto na educação pública em redes estaduais de ensino, a partir de 1990, por regiões brasileiras e por estado.

A autora mostra por meios dos dados analisados a desigualdade em geração de riqueza entre as regiões brasileiras. O menor PIB fica na região norte e nordeste, além de que as diferenças permanecem entre os estados dessas mesmas regiões. Farenzena afirma que as diferenças do PIB influenciam na capacidade de financiamento da educação básica, pois são as receitas resultantes de impostos dos governos que são mais significativas.

O processo de municipalização também é discutido pela autora, o qual foi induzido pelo FUNDEF. Todavia, existem estados que já haviam iniciado o processo de municipalização por outros fatores, dentre eles crise fiscal do estado e ideia de descentralização.

A autora selecionou os anos de 2004, 2006 e 2010 para a análise. De 2004 para 2006, o gasto anual por aluno aumentou nos estados, exceto nos estados de Rio Grande do Sul e Alagoas. Comparando 2004 a 2010, todos os estados obtiveram aumento no gasto aluno/ano.

A autora Rosana Evangelista da Cruz traz uma análise da gestão dos recursos federais na política da educação básica, enfocando programa Fundo Nacional de Desenvolvimento da Educação (FNDE), no artigo "Os recursos federais para o financiamento da educação básica".

A autora expõe que o MEC (Ministério da Educação e Cultura) é responsável pelo curso das políticas educacionais do governo federal, pois essa é uma atribuição da União. Todavia, a União direciona a maior parte dos recursos federais para o ensino superior.

Dessa maneira, objetivando a universalização do ensino obrigatório e a função supletiva e redistributiva, a União necessita do FNDE, o qual auxilia no financiamento da educação pública obrigatória nos estados e municípios.

Os dados apresentados pela autora mostram que em $2011,78,8 \%$ dos recursos do FNDE foram geridos pelo MEC, em que três programas possuem quase a totalidade dos recursos financeiros executados pelo FNDE, a saber: Projovem (100\%), Brasil Alfabetizado e EJA (99\%) e Brasil Escolarizado (96\%).

Por fim, a autora conclui que a União desenvolve estratégias para cumprir o exposto no artigo 211 da Constituição Federal, ou seja, exercer sua função supletiva e redistributiva.

O quinto artigo, intitulado "Constrangimentos socioeconômicos no acesso à educação superior no Brasil", autoria de Nelson Cardoso Amaral discutir o acesso ao ensino superior, trazendo dados que buscam analisar 
as informações financeiras dos censos financeiros da educação superior e dados de execução orçamentária do governo federal.

Por meio dos dados, o autor mostra que as Instituições de Educação Superior (IES) municipais e privadas tem a maior parte do financiamento com receitas próprias. As IES estaduais e municipais obtém a maior parte de seu financiamento com receitas de transferência.

O autor analisa a meta 12 do Plano Nacional de Educação (2014-2024), a qual discorre acerca da universalização do ensino superior, propondo-se em elevar a taxa de matrícula líquida no ensino superior em 33\% até o último ano de vigência do PNE. Em 2009, esse percentual correspondia a 15 \%.

Amaral destaca que em 2009, 74,4\% das matrículas no ensino superior no Brasil eram em IES privadas. Comparando com alguns países, o Brasil possui percentual menor apenas que o Chile (76,65\%), a Coreia do Sul $(80,2 \%)$ e o Japão $(79,2 \%)$. Além disso, a análise do autor mostra que em 2023 , as matrículas no ensino superior no Brasil continuariam no setor privado.

O autor afirma que para universalizar o ensino superior é necessário também atuar massivamente no ensino médio, pois o número de concluintes é baixo. Assim, é importante elevar o percentual de concluintes o ensino médio para que sejam habilitados a cursar o ensino superior.

O artigo "As relações entre o público e o privado na oferta educacional no Brasil", de autoria de Theresa Adrião busca discutir, de um modo geral, a influência do setor privado na educação. A autora relata que, muitas vezes, tem-se a falsa ideia de que a qualidade está no setor privado.

Essa ideia concretiza-se nas parcerias entre os estados e municípios com o setor privado, como por exemplo, na assessoria a gestão de educação, compra de materiais didáticos do setor privado para ser utilizado em escolas públicas, dentre outros.

Além disso, como afirma a autora, a Lei de Diretrizes e Bases da Educação Brasileira (LDB) permite que os recursos públicos sejam destinados a instituições privadas na educação, respeitando algumas observações.

Em defesa da esfera pública, a autora conclui que é necessário fortalecer e qualificar a gestão pública, almejando-se a articulação entre união, estados, distrito federal e municípios, além do apoio financeiro da união.

O autor Paulo Sena analisa o financiamento da educação no Legislativo no artigo intitulado "O financiamento da educação no Legislativo". O autor relata que após 1988 o financiamento da educação teve importantes dispositivos.

Segundo Sena, o Legislativo tem desempenhado um importante papel frente ao financiamento da educação, contrariando a ideia de que atuava como coadjuvante do Poder Executivo. Assim, o autor elabora um quadro, com leis relacionadas ao financiamento da educação, mostrando que o Legislativo tem atuado nessa área.

Além disso, salienta a importância do Legislativo, pois os movimentos sociais podem fortalecer suas propostas por meio das audiências públicas.

O artigo "Controle estatal ou social das verbas de educação?", de autoria de Nicholas Davies busca discutir o controle da aplicação de verbas da educação a partir dos relatórios dos tribunais de contas de estados e municípios e do controle social dos conselhos do FUNDEB.

O autor afirma que alguns tribunais de contas (TCs) possuem muitas informações, enquanto outros não seguem as normas estabelecidas pela LDB e nem as normas da Secretaria do Tesouro Nacional para elaboração dos relatórios. Além disso, afirma que, às vezes, os gastos são contabilizados em diferentes órgãos, dificultando a análise de todos os gastos.

$\mathrm{Na}$ análise dos relatórios, o autor encontrou diversos equívocos, como, por exemplo: pagamento do pessoal inativo da educação como remuneração e não proventos.

Em relação aos conselhos do FUNDEB, o autor salienta que esses podem funcionar mais na teoria, pois o potencial democrático desses é limitado, visto que são mais estatais que sociais, pois possuem mais representantes do Estado de que da sociedade. 
O autor José Marcelino Pinto, no artigo "Dinheiro traz felicidade? A relação entre insumos e qualidade na educação" discute a complexidade entre insumos e qualidade na educação, dialogando com outros autores.

O autor afirma que o nível socioeconômico da família está relacionado com o desempenho do estudante, sendo essa uma crítica do autor aos testes padronizados, os quais não consideram esse elemento.

Segundo Pinto, os testes são importantes, porém, devem considerar outros fatores. O "ranking" de escolas na percepção do autor é negativo, pois ocasiona fuga de professores e diretores.

O autor salienta que falta um sistema nacional de educação, pois o que existem são amontoados de testes, os quais não expressam totalmente a realidade brasileira. Além disso, afirma que o dinheiro faz diferença na qualidade do ensino, tendo-se as escolas técnicas federais, em relação ao gasto-aluno, como exemplo a ser seguido.

Por fim, o artigo "Financiamento e remuneração docente na educação básica", de autoria de Márcia Aparecida Jacomini, Maria Angélica P. Minhoto e Rubens Barbosa de Camargo busca analisar aspectos quanto ao vencimento, carreira e remuneração docente em doze estado brasileiros e suas capitais, no ano de 2010, sendo fruto de uma pesquisa nacional financiada pela CAPES.

Os autores salientam que a remuneração docente integra os insumos necessários para a qualidade da educação, a qual é composta pelo vencimento e vantagens pecuniárias. Além disso, a remuneração docente é definida a partir de cada esfera administrativa.

A análise dos planos de carreira realizada pelos autores mostra que em todos os estados da pesquisa, temse diferença no vencimento de acordo com o nível de formação.

Os autores afirmam, por meio de dados analisados, que em 2010 cinco estados e dois municípios tiveram o valor hora-aula abaixo do estabelecido pelo Piso Salarial Profissional Nacional, sendo eles: Minas Gerais, Santa Catarina, Rio Grande do Norte, Rio Grande do Sul, Pará, João Pessoa e Florianópolis.

Segundo os autores, a dispersão salarial, o que corresponde a distância entre menor e maior remuneração, do início ao fim da carreira (DUTRA JUNIOR apud JACOMINI et al, 2014, p. 180) é maior nas redes municipais comparadas as redes estaduais, o que pode demonstrar maior atratividade da carreira no âmbito estadual do que municipal.

A obra "Para onde vai o dinheiro? Caminhos de descaminhos do financiamento da educação" traz inúmeras contribuições para a educação. Os artigos abordam questões importantes, em que um complementa o outro.

A leitura do livro permite concluir que o financiamento é um dos elementos que pode proporcionar a melhoria educacional, a qual está relacionada com a qualidade da educação, universalização da educação, acesso, permanência, dentre outros. 


\title{
RESUMOS DE TESES E DISSERTAÇÕES
}

\section{A disformidade no desenho da oferta educacional e a fragilização do direito à educação: um panorama da oferta de matrículas do ensino fundamental no Brasil}

\author{
Autora: Marilene Zampiri \\ Nível: Doutorado (PPGE/UFPR) \\ Orientador: Prof. Dr. Ângelo Ricardo de Souza
}

Esta pesquisa examina as formas de entrada nos processos de escolarização pública como condição primordial ao acesso e fruição ao direito à educação, tendo por base o pacto federativo reorganizado na Constituição Federal de 1988 e a assimetria socioeconômica que marca os entes federados. O objetivo dessa análise foi compor um panorama das formas acordadas entre os entes federados, estado e municípios, para a oferta de matrículas públicas. O estudo está circunscrito ao ensino fundamental, o qual, instituído como direito público subjetivo, impõe ao Estado o dever na sua disponibilização material e, ao mesmo tempo, impede o sujeito deste direito a sua alienação ou recusa. A investigação mostrou que, apesar da Constituição Federal de 1988 indicar o regime de colaboração como instrumento para modelar os acordos na responsabilização com os encargos educacionais, ao não regulamentá-lo, abriu possibilidade para elaboração de variadas formas nos acordos, mais precisamente, tantos quantos são os entes federados, já que todos são autônomos e legalmente estão aptos a formular suas próprias políticas educacionais. Concomitantemente, foram consideradas as políticas de fundos (FUNDEF e FUNDEB) como delimitadoras do período analisado, tendo em vista que tais políticas, especialmente o FUNDEF, porque focado no ensino fundamental, influenciou fortemente a transferência e assunção dos encargos educacionais entre os entes federados, consequentemente, influenciando o desenho da oferta no Brasil. Portanto, o estudo restringiu-se à análise das matrículas em três ocasiões: 1996 (antes da vigência do FUNDEF), 2006 (fim da vigência do FUNDEF e ano anterior ao funcionamento do FUNDEB) e 2012 (situação mais recente de informações de matrículas). As informações das matrículas, organizadas a partir de dois critérios, a oferta partilhada entre os dois níveis administrativos (municipal e estadual) e a oferta exclusiva de um ou outro, revelaram um quadro disforme na modelagem dos acordos para a oferta educacional, tanto entre as unidades federativas como entre as fases desta etapa da educação básica, anos iniciais e finais. A ausência de uma articulação entre os entes federados produziu um panorama marcado por modelos disformes e não vinculados à equalização das trajetórias educacionais e, desta maneira, com boa probabilidade de fragilizar o direito à educação. Assim, o Estado deixa de cumprir o dever constitucional da distribuição material do direito reconhecido socialmente e protegido juridicamente. O estudo mostra que superar a desigualdade no acesso e fruição do direito requer, antes de tudo, enfrentar a disformidade no quadro de oferta dos encargos educacionais.

Palavras-chave: Direito à educação. Políticas Educacionais. Ensino fundamental. Federalismo. Regime de colaboração. 